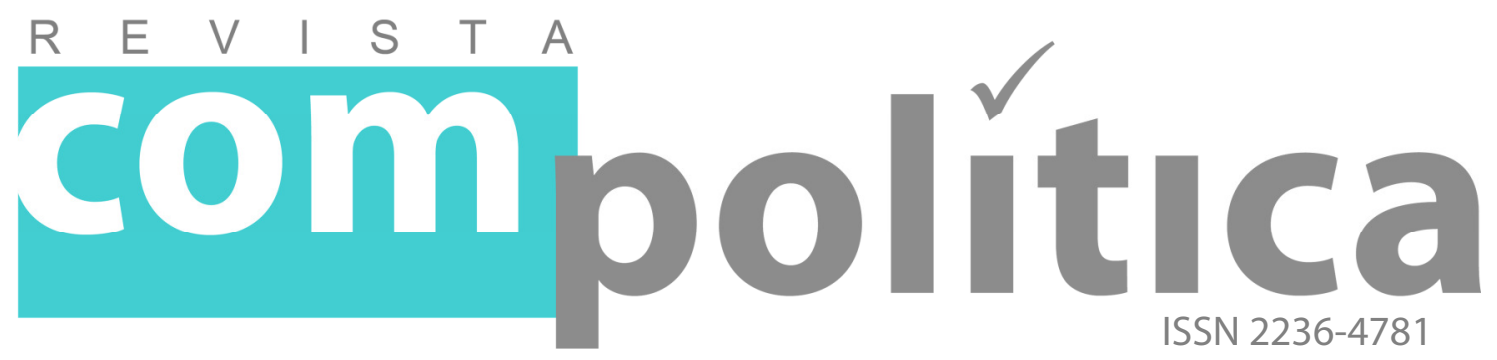

FERNANDES, Luiz Carlos do Carmo

Mestre em Comunicação pela Faculdade de Comunicação e Biblioteconomia da UFG e doutorando em Sociologia pela Faculdade de Ciências Sociais da UFG.

<lucajor@gmail.com>

\title{
Tecnologia a serviço da cidadania política
}

\section{RESUMO}

Este artigo discute as transformações da cidade, o ideal moderno do espaço público e a vida nas metrópoles para trazer a tona os problemas urbanos e a perspectiva de um caminho político para o seu enfrentamento: a cidadania ativa. Tendo como base os avanços da democracia representativa no Brasil pós-constituição de 1988 -, em particular o orçamento participativo, os conselhos de política e os planos diretores municipais -, busca confirmar a impressão de que a solução dos problemas das cidades, em particular das regiões metropolitanas brasileiras, passam pela questão do fortalecimento da cidadania política e do maior envolvimento do cidadão com as questões da cidade. Neste sentido, apontam as novas tecnologias baseadas na internet como ferramentas importantes nesta luta.

Palavras-chaves: Metrópole, Instituições Participativas e Novas Tecnologias.

\section{ABSTRACT}

This article discusses the changes in town, the modern ideal of public space and life in the metropolis to bring out urban problems and the prospect of a political path for your coping: active citizenship. Based on the advances of representative democracy in Brazil after the 1988 constitution - in particular the participatory budget, the policy advice and municipal master plans - seeks to confirm the impression that solving the problems of the cities, in particular Brazilian metropolitan regions, go through the issue of strengthening of political citizenship and greater citizen involvement in city issues. In this sense, suggest new internet-based technologies as important tools in this fight.

Keywords: City, Representative Democracy and New Technologies. 


\section{Tecnologia a serviço da cidadania}

\section{[Technology in the service of citizenship]}

FERNANDES, Luiz Carlos do Carmo

\section{Introdução}

cidade passou por várias transformações ao longo dos últimos
dois séculos e vem se transformando de forma ainda mais acelerada neste terceiro milênio. O que permitiu Lefebvre (2001) apontar a morte da velha cidade, que não seria hoje mais do que um “objeto de consumo cultural”. Segundo o autor francês, o que ainda existe é o urbano, que "persiste no estado de atualidade dispersa e alienada": uma espécie de embrião de virtualidade. (LEFEBVRE, 2001 p.106). Assim, "o direito à cidade não pode mais ser concebido como simples direito de visita ou de retorno às cidades tradicionais, uma vez que só pode ser formulado como direito à vida urbana." (Idem, Ibidem)

As mudanças econômicas, políticas, culturais e sociais na cidade foram tantas que já não a permite mais cumprir a promessa iluminista de incorporação do estranho por meio de espaços públicos que possam acolhê-lo. Ao contrário. Na cidade da pós-modernidade, as consequências perversas da globalização - desindustrialização, desregulamentação, individualização, presentificação, exclusão etc. acirram ainda mais os conflitos gerados pela lógica da escassez; pelo não cumprimento da promessa de acesso ao consumo.

Já não há mais, de forma predominante, a noção de vizinhança, o senso de camaradagem, apontados por Park (1973) ao apresentar o comportamento humano no meio urbano. Muito menos, a ideia de comunidade urbana (WEBER, 1973) ou de que " o indivíduo somente 
se torna eficaz através de grupos organizados" (WIRTH, 1973, p.113). O que prevalece na cidade é espaço de luta, apresentado por Carlos (1992). Um espaço produzido em função das condições de reprodução do capital, mas também em função das condições de reprodução da vida humana (CARLOS, 1997, p. 84).

Como afirma Gottdiener (1993):

O Sistema atual nos dividiu em proprietários e locatários, em condutores de automóveis e usuários do transporte coletivo, em empregados de altos salários e os ultrapassados economicamente - em suma, aqueles que tiram proveito das relações de propriedade existentes, sejam elas medidas por meios públicos ou privados, e aqueles que são vítimas dessas relações (GOTTDIENER,1993, p.152)

As demandas do ideal moderno de espaço público: acessibilidade, comunidade e consumo acessível são negados a uma larga camada dos habitantes das cidades. Excluídos da possibilidade de se integrarem como força produtiva no atual estágio do capitalismo, sem perspectivas de futuro, restam-lhes a informalidade, quando não a ilegalidade e a criminalidade, como forma de sobrevivência.

De acordo com Bauman (2007) - trabalhando com os conceitos de Robert Castel -, a "modernidade líquida" teria trazido de volta as “classes perigosas". Com uma grande diferença: as "classes perigosas" originais eram compostas de pessoas temporariamente excluídas e as atuais o é por pessoas incapacitadas para a reintegração, que formam a chamada "subclasse" ou "subcidadãos".

Do outro lado, estão as elites globais, que se deslocam sem ter qualquer compromisso com as cidades, sem qualquer identidade local. Com sua ideologia do desempenho, com a política da

\footnotetext{
${ }^{1}$ Para Souza (2003), subcidadãos são pessoas sem acesso completo, principalmente, aos direitos de segunda geração, mas que, também, não estão totalmente excluído da sociedade. Algo muito próximo do que Castells denomina com "vítimas da exclusão social" (CASTELLS, 1999, p,98).
} 
meritocracia, negam o acesso ao consumo a grande parte da sociedade e transformam as cidades em "um depósito de problemas causados pela globalização" (BAUMAN,2007,p. 32).

O resultado é que as metrópoles ficam assim divididas em "zonas luminosas" e "zonas perigosas"; entre condomínios fechados e favelas, alimentando a mixofilia e a mixofobia, que coexistem nas cidades e em cada cidadão. (BAUMAN, 2007, p. 48). o que transforma o espaço público das cidades em um espaço de anomia. Como indica Bauman "paradoxalmente, as cidades - que na origem foram construídas para dar segurança a todos os seus habitantes - hoje estão cada vez mais associadas ao perigo" (Idem, p.40).

A tese de que a sociabilidade é a medida para a segurança, apresentada por autores como Jacobs (2000), é substituída pela lógica do hedonismo. O divino social de Durkheim, a comunidade de sentidos de Weber são trocados pelos subgrupos; pelas tribos afetivas (MAFFESOLI, 2000). Ou seja, as identidades não têm forte peso na formação dos grupos. O que prevalece é a busca do prazer imediato; o sentir-se bem.

Uma lógica que é explicada por Robert Castel, como bem lembra Bauman (2007). O autor afirma que Castel culpa as manifestações de insegurança moderna ao individualismo, ao lembrar que a sociedade moderna substituiu as comunidades solidariamente unidas e as corporações que outrora definiam as regras de proteção pelo dever individual de cuidar de si próprio e de fazer por si mesmo, esquecendo de que a proteção só pode ser coletiva". Melhor dizendo: a supervalorização do individuo resultou na sua própria fragilidade e vulnerabilidade (BAUMAN, 2007, ps. 16-17).

O que se vê atualmente nas cidades, principalmente as com características de metrópole ${ }^{2}$ é um cenário de disputa, conflito,

\footnotetext{
${ }^{2}$ Segundo dados do IBGE baseados no Censo 2010, 36,2\% da população brasileira estão concentrados nas 15 principais regiões metropolitanas brasileiras.
} 
violência e insegurança, muito propício para o desenvolvimento do que Pastana (2005) denomina de Cultura do Medo. “ (...) o que se observa hoje é uma verdadeira cultura do medo, onde a busca pela proteção contra o crime torna-se, ao mesmo tempo, obsessão e produto" (PASTANA, 2005, p.190). Segundo a autora, trata-se de uma forma hegemônica de pensar sobre a criminalidade, que permite a manutenção de práticas autoritárias mesmo num contexto político democrático.

Relembrando Boaventura Souza Santos (1999, p. 130), Pastana afirma que estas práticas autoritárias são exercidas numa combinação com outras práticas que tentam destituir a cidadania de valor social, como o clientelismo, o nepotismo, a corrupção, entre outros métodos antidemocráticos tão comuns no Brasil. Como bem explica Cabral Neto (1997):

As especificidades brasileiras traduzem-se na edificação de uma sociedade com pouca ou quase nenhuma tradição democrática. Nela o conservadorismo está imbricado, não apenas no aparelho de Estado, mas atravessa, de ponta a ponta, toda a sociedade civil. As regras do jogo democrático, definidas predominantemente pelas elites em função dos seus interesses particulares, têm dificultado tanto a participação política mais abrangente da sociedade civil, principalmente das massas desorganizadas, quanto o acesso aos bens materiais e culturais socialmente produzidos. (CABRAL NETO,1997, p.307)

Fica claro assim que a questão da violência na cidade, como muitas outras questões envolvendo a vida urbana hoje, não pode ser pensada de forma isolada e precisa ser vistas, muito mais, como uma questão política do que propriamente uma demanda de segurança pública. Como afirma Weber (1973), o fenômeno urbano só pode ser estruturado no plano político.

O que é pode ser traduzido nas palavras do sociólogo Alessandro Baratta, citado por Coimbra (1995): “A resposta ao problema da criminalidade e do medo só poderá ser efetiva, e não ilusória, se os 
cidadãos deixarem de ser espectadores dos meios de comunicação e da política como espetáculo, para serem atores." (BARRATA, 1994, p.18). Ou seja, é preciso um maior envolvimento político do cidadão na resolução dos problemas da cidade.

Mas não deve ser entendido como uma proposta de substituição da democracia representativa pela democracia direta, pois como afirma Bobbio (1987) citado por Cabral Neto (1997), “[...] hoje [...] um desenvolvimento da democracia, [...] consiste não tanto [...] na substituição da democracia representativa pela democracia direta, [...] mas na passagem da democracia na esfera política [...] para a democracia na esfera social (BOBBIO, 1987, p. 155-156).

Neste sentido cabe ressaltar a experiência brasileira pós Constituição de 1988. Como lembra Avritzer (2008), "O Brasil se transformou ao longo do século XX de um país de baixa propensão associativa e poucas formas de participação da população de baixa renda [...] em um dos países com maior número de práticas participativas." (AVRITZER, 2008, p.44).

O autor faz algumas considerações importantes sobre o desenho institucional da democracia brasileira que parecem contribuir para que a discussão possa ser aprofundada neste sentido. Ao estudar o tema, constrói o conceito de "instituições participativas", as definindo a partir de três características básicas: 1 ) ser pautada na ideia de uma política construída de baixo para cima; 2) ser pautada na ideia de partilha de poder, e constituídas pelo próprio Estado, com representação mista de atores da sociedade civil e atores estatais e 3) possuir desenho institucional de ratificação (Idem, Ibidem).

O primeiro caso de instituições participativas é exemplificado pelo orçamento participativo; o segundo, pelos conselhos de política e o terceiro, pelos planos diretores municipais. Depois de analisar os três casos, a conclusão de Avritzer é de que os desenhos de baixo para cima são os mais fortemente distributivos; os desenhos de partilhas 
são os mais fortemente democratizantes. E os casos de ratificação são os mais efetivos quando há necessidade de sanção por parte do judiciário e do ministério público (AVRITZER, 2008, p.60).

A análise consegue desenhar uma tipologia das instituições participativas no Brasil depois da Constituição de 1988: O desenho de baixo para cima (orçamento participativo) possui alta capacidade democratizante e alta efetividade/dependência do sistema político; o desenho de partilha (conselhos políticos) possui média capacidade democratizante e média efetividade/dependência do sistema político. Finalmente, os casos de ratificação (plano diretor municipal) possuem baixa capacidade democratizante e baixa efetividade/dependência do sistema político (idem, Ibidem).

Ribeiro, Santos Jr e Azevedo (2009), por sua vez, aprofundaram ainda mais a perspectiva da sociedade brasileira em conciliar a democracia representativa com a democracia direta. Os autores procuraram analisar de forma comparada a realidade dos conselhos de política, tendo em vista a diversificada (e complexa) realidade social, econômica e política dos municípios do país. Tomando como base os dez anos de experiência dessas instâncias deliberativa e com base no estudo realizado nas regiões metropolitanas do Rio de Janeiro, Belo Horizonte, São Paulo, Recife e Belém, os autores apontam a percepção de que os conselhos municipais constituem instrumento de democratização da gestão pública local.

[...] podemos afirmar que os conselhos são espaços institucionais com potencial de se transformarem em instrumentos da constituição da governança democrática ${ }^{3}$ dos municípios. [...] os conselhos estão se constituindo em arena de interação entre governo e a sociedade [...] criando, portanto, condições para a instauração de processos consensuais de tomada de decisão e aumento da eficácia e

\footnotetext{
${ }^{3}$ Os autores definem governança democrática como "os padrões de interação entre as instituições governamentais, agentes do mercado e atores sociais que realizem a coordenação e, simultaneamente promovam ações de inclusão social e assegurem a ampliem a mais ampla participação social nos processos decisórios em matéria de políticas públicas."
} 
efetividade das políticas públicas locais. (SANTOS; RIBEIRO JR E AZEVEDO, 2004,p. 47)

E importante identificar neste trabalho a preocupação teórica no sentido de maior envolvimento político do cidadão na resolução dos problemas da cidade. Ao estabelecer o conceito de governança democrática, Santos Jr, Ribeiro e Azevedo destacam três características básicas desse novo padrão de governo: maior responsabilidade dos governos municipais em relação às políticas públicas e às demandas de seus cidadãos; o reconhecimento de direitos sociais; a abertura de canais para a ampla participação cívica da sociedade.

Trata-se de um modelo que parte da crítica à ilusão do governo tecnocrático, mas que recusa simultaneamente a concepção liberal de participação. Os autores se baseiam no conceito de poliarquia de Dahl (1997) para deixar claro que a proposta de governança democrática implica que para efetividade do regime democrático não basta a realização de eleições competitivas, mas um conjunto de liberdades que asseguram o exercício dos direitos de cidadania.

Partindo destes princípios, eles afirmam que a institucionalização do modelo de governança democrática depende dos arranjos no sentido de: (i) bloquear ou minimizar as políticas clientelistas vigentes e a captura das esferas públicas por interesses coorporativos e particulares, através de procedimentos institucionais, como também pela disseminação de uma cultura democrática que incorpore às práticas dos atores e que possa sobrepor-se hegemonicamente á cultura política não-democráticas presente no sistema público brasileiro; (ii) gerar práticas e estruturas horizontais de participação capazes de produzir "capital social" ; (iii) "empoderar" grupos

\footnotetext{
${ }^{4}$ Para Putnam, o capital social refere-se "a características da organização social, como confiança, normas e sistemas que contribuam para aumentar a eficiência da sociedade, facilitando as ações coordenadas" (PUTNAM, 1996:177). Diferente do
} 
sociais em situação de vulnerabilidade e exclusão de forma a reduzir o impacto das relações assimétricas de poder; (iv) reforçar vínculos associativos dos grupos locais, suas mobilizações representativas, de forma a incentivar e fortalecer as relações de interações entre os diferentes atores com presença na esfera pública (RIBEIRO, SANTOS JR E AZEVEDO, 2004, pgs. 15-21).

Tende-se a concordar com esta perspectiva neste artigo, mas também se pretende ampliar as possibilidades das esferas participativas até aqui propostas trazendo para debate a visão apontada por Cabral Neto (1997)

[...] à discussão sobre a ampliação da dimensão política da democracia deve ser incorporado um outro elemento de igual importância: a condição socioeconômica dos atores sociais que estão envolvidos no jogo democrático. Além da elevação do número de eleitores e das instâncias onde eles devem exercer o seu direito de voto, é preciso levar em conta o crescimento qualitativo do eleitorado, no que diz respeito ao seu nível de vida, de escolarização e às condições objetivas de participar das decisões políticas, dos processos administrativos e de exercer o controle sobre os seus representantes.

Cabral Neto (1997) conclui que o defeito da democracia representativa não é o de ser representativo, mas de não sê-lo o bastante. Assim, sugere que a ampliação da representação passaria, necessariamente, pela criação de condições favoráveis no sentido de que o cidadão passasse a interferir concretamente nas decisões sociais e econômicas por meio dos órgãos de decisão política. A questão, pois, não é a de negar o sistema de representação, mas acionar mecanismos capazes de aperfeiçoá-lo no interior mesmo da sociedade capitalista.

capital tradicional, que diminui com o uso, o "capital social" aumenta proporcionalmente a sua utilização. 


\section{Redes Sociais}

Isso, nos leva a sugerir o uso da internet como aliado nesta cruzada, tendo em vista as características da vida urbana hoje, cada vez mais perpassada pela gramática da Nova Cultura Política. Clark e Navarro (2007) chamam a NCP de uma política pós-industrial com novas regras em relação aos modos clássicos de clientelismo e política de classes. Segundo eles, boa parte dos processos da vida cotidiana se relaciona com o consumo e estilos de vida, não mais com as abstrações ideológicas. Ou seja, a música, os carros mais velozes, a cerveja mais saborosa, os vídeos games, a internet são assuntos mais imediatos na preocupação do cidadão médio do que os relacionados à política (CLARK E NAVARRO, 2007, p.28). ${ }^{5}$

Como afirma David Eaves ${ }^{6}$, "a tecnologia é essencial para o desenvolvimento de um país plural e democrático". o pesquisador defende que as democracias modernas, em especial aquelas mais jovens, como a do Brasil, só amadurecerão quando a tecnologia se tornar uma ferramenta ativa para a divulgação e democratização das informações governamentais e de interesse público.

\footnotetext{
${ }^{5}$ Ao abordar a questão da Nova Cultura Política, não se pode deixar de registrar as ressalvas apresentadas por Ribeiro, Santos Jr. e Azevedo (2009) em relação à NCP. De acordo com eles, há limites nas possibilidades de abordagem na NPC para análise dos países emergentes. No estudo que realizaram em São Paulo e Porto Alegre, Rio de janeiro, Belo Horizonte, Recife, Goiânia e Natal, para verificar os impactos políticos da globalização nas principais regiões metropolitanas do Brasil, eles concluíram que, das sete características da NCP apenas três delas podem ser identificadas claramente no Brasil: o crescimento concomitante do individualismo de mercado e da responsabilidade social; o questionamento do Estado do BemEstar Social, e a existência dos mais fervorosos defensores da NCP nas sociedades menos hierárquicas e entre os indivíduos mais jovens, mais instruídos e os que vivem mais confortavelmente. E, mais especificamente, em duas regiões metropolitanas que possuem maior tradição política e de mobilização social: São Paulo e Porto Alegre.

${ }^{6}$ Pesquisador canadense que é um dos principais expoentes do Open data movimento que defende a transparência dos dados públicos. Entrevista publica no Jornal Correio Braziliense em 13/05/2011.
} 
O potencial da internet para o reforço de pelo menos três itens propostos dentro da governança democrática ${ }^{7}$ pode ser explicada por Pereira (2011), com o que ele chama de apropriação política da rede. Segundo o autor o intenso fluxo de informação na rede, que é multidirecional, ampliou o debate e também a visibilidade das críticas, o que vunerabiliza as imagens políticas construídas, e faz com que os atores políticos sejam atingidos por mobilizações online, mesmo que elas não tenham grande repercussão nas ruas. A Lei Ficha Limpa, as construções colaborativas da Constituição da Islândia, do Marco Civil e da Lei de Direito Autoral brasileiro, as insurreições no Egito e na Líbia e também a organização de protestos pela sociedade civil brasileira, como a Marcha pela Liberdade de Expressão, a Marcha da Maconha, o Churrascão da Gente Diferenciada, o Movimento Passe Livre e o Movimento Caras Pintadas Contra a Corrupção II, são alguns bons exemplos disso (Pereira, 2011, p.5).

Cabe lembrar também o twitaço em favor da campanha "Banda Larga é um Direito Seu", uma campanha promovida por cerca de 60 entidades sociais que defendem um serviço de acesso à internet mais barato, de melhor qualidade e oferta universalizada, e buscam evitar que o Plano Nacional de Banda Larga (PNBL) seja transferido para as operadoras privadas. $O$ resultado conseguido em um dia foi mais de três mil postagens, 1474 twitters em apenas uma hora e a adesão de cerca de 1600 pessoas no Facebook. E mais uma manifestação pública do ministro das comunicações, Paulo Bernardo. Ao saber da extensão do twitaço, ele precisou se manifestar publicamente sobre a questão,

\footnotetext{
${ }^{7}$ No caso, (ii) gerar práticas e estruturas horizontais de participação capazes de produzir "capital social" ; (iii) "empoderar" grupos sociais em situação de vulnerabilidade e exclusão de forma a reduzir o impacto das relações assimétricas de poder; (iv) reforçar vínculos associativos dos grupos locais, suas mobilizações representativas, de forma a incentivar e fortalecer as relações de interações entre os diferentes atores com presença na esfera pública.
} 
dizendo que não iria perder tempo com a manifestação on-line e que as pessoas teriam o direito de se divertirem. ${ }^{8}$

Outro exemplo que não poderia deixar de citar são as manifestações de rua contra o aumento das passagens do transporte coletivo, que acabou sendo ampliado por novas bandeiras, como o combate à corrupção e a PEC 37, denominada por alguns de "primavera brasileira". Elas reforçam ainda mais esta ideia de que a internet é importante para a mobilização política da sociedade e joga por terra uma das principais críticas aos defensores da utilização da internet para as ações políticas: a de que o uso da tecnologia não produz níveis mais elevados de participação política e, por isso, e não consegue alcançar efeitos mais duradouros que possam repercutir na sociedade com um todo.

Mais do que os resultados conhecidos de tais manifestações, que se sucederam em todo o Brasil, numa proporção vista neste período de redemocratização apenas na campanha das Diretas-Já, Impeachment de Collor e nas Paradas Gay; ajudam neste sentido os dados divulgados por pesquisa Ibope ${ }^{9}$, os reflexos nos índices de aprovação da presidenta Dilma e na confiança nas instituições democráticas do país $^{10}$. Ou seja, as discussões em redes sociais como o Facebook e o Twitter ajudaram os manifestantes a criar capital social, empoderarem-se, a reforçar vínculos associativos e a realizar mobilizações representativas para marcar presença na esfera pública e

\footnotetext{
${ }^{8}$ A ação do ministro, ao que parece, uma clara tentativa de desvalorizar a mobilização, seria desnecessária caso a repercussão, inclusive na imprensa, não tivesse sido maior que o esperado.

9 Segundo dados da pesquisa Ibope encomendada pela Rede Globo, 46\% dos manifestantes nunca tinham participado de manifestação política, $78 \%$ se organizaram pelas redes sociais e $52 \%$ eram estudantes; $43 \%$ deles com menos de 24 anos.

${ }^{10}$ A popularidade da presidente Dilma Rousseff caiu 27 pontos, em três semanas de protestos nas ruas do Brasil, segundo pesquisa DataFolha. Já a pesquisa de Confiança Social, realizada pelo Ibope Inteligência, demostrou uma queda da confiança em todas as instituições (em média de 11,27\%); com exceção das redes sociais, formada pela família, amigos e vizinhos, que permaneceram no mesmo patamar de confiança ou cresceram dentro da margem de erro.
} 
definir suas opiniões e posições a cerca dos temas relevantes e de interesse público.

Esses exemplos servem para demonstrar o potencial das redes sociais para o fortalecimento da democracia representativa, na perspectiva de Miguel (2003), que defende a hipótese de que a informação é relevante no processo político e por isso demanda o pluralismo político da mídia - que permitiria ao cidadão, em sua condição de consumidor de informação, ter acesso a valores, argumentos e fatos que instruem as correntes políticas em competição e possa formar, de modo abalizado, sua própria opinião política - e o pluralismo social, que seria a disseminação das visões de mundo associadas às diferentes posições no espaço social, que são a matéria-prima na construção das identidades coletivas.

Uma perspectiva mais contra hegemônica, que permitiria a existência do que Beck (1995) chama de subpolítica. Essa, segundo o autor, distingue-se da "política" porque permite que os agentes externos ao sistema político ou corporativo apareçam no cenário do planejamento social (...) e porque não somente os agentes sociais coletivos, mas também os indivíduos competem (...) um com o outro pelo poder de conformação emergente do político (BECK, 1995, p. $34)$.

\section{Conclusão}

Assim, conclui-se com a impressão de que os problemas das cidades, em particular das regiões metropolitanas brasileiras passam pela questão do fortalecimento da cidadania política e do maior envolvimento do cidadão com as questões da cidade. Entende-se, como afirmam diversos autores aqui citados (AVRITZER, 2008; RIBEIRO, SANTOS JR E AZEVEDO, 2004 e 2009) que o Brasil tem desenvolvido práticas participativas bastante interessantes, como o 
orçamento participativo, os conselhos políticos, os planos diretores das cidades e até mesmo os conselhos tutelares - como demonstra Borges (2009).

Ao que poderia, acredita-se, ser acrescido como aliada, as novas tecnologias baseadas na internet, em particular as redes sociais. Como afirmam Zhang, Johnson, Seltzer e Bichard (2009), "[...] a discussão da política com os de perspectiva diferentes gera resultados positivos democráticos, tais como o aumento do conhecimento político e da tolerância" (ZHANG, JOHNSON, SELTZER E BICHARD, 2009, p.87)

Isso, levando-se em conta as ressalvas apresentadas por Fernandes e Almeida (2010): “[...] apesar de a ferramenta de micromensagem ${ }^{11}$ promover o aumento da proximidade entre políticos e cidadãos, o estímulo à participação política ainda depende da ampliação de uma cultura de envolvimento político, sem a qual os meios de comunicação, quaisquer que sejam, não são mais que um disseminador de informações" (FERNANDES E ALMEIDA, 2010, p.18).

\footnotetext{
${ }^{11}$ Os autores tratam do caso específico do Twitter, mas entendemos servir também para outras redes sociais on-line.
} 


\section{Referências}

AVRITZER, Leonardo. "Instituições participativas e desenho institucional: Algumas considerações sobre a variação da participação no Brasil democrático" in: Opinião Pública, Campinas, vol.14, n¹/ Julho 2008- p.43 a 64.

BAUMAN, Zygmunt. Confiança e Medo na Cidade. Rio de Janeiro: Jorge Zahar Editora, 2007.

BECK, Ulrich. A reinvenção da política: Rumo a uma teoria da modernização Reflexiva. In: BECK, U., GIDDENS, A., LASH, S. Modernização Reflexiva: Política Tradição e Estética na Ordem Social Moderna. São Paulo: Editora Unesp, 1995.

BORGES, Pedro Célio A. Mudanças e reprodução política no novo associativismo. Notas sobre significado e alcance democrático dos conselhos municipais de políticas setoriais. XIV Congresso Brasileiro de Sociologia GT-8 - Rio de Janeiro: Sociedade Brasileira de Sociologia, 2009.

CABRAL NETO, Antônio. Democracia: velhas e novas controvérsias. Estudos de Psicologia. Natal,2(2) :287-312, jul-dez.1997.

CARLOS, Ana Fani. A cidade. São Paulo: Editora Contexto, 1992

CLARK, Terry N. y Navarro, Clemente J. "Palabras preliminares" e "La Nueva Cultura Política: como agenda de investigación”. In : CLARK y NAVARRO, C. La Nueva Cultura Política: tendências globales y casos iberoamericanos. Buenos Aires: miño y dávila editores, 2007 - p. 21 a 49.

COIMBRA, Cecília Maria B. Produção do Medo e da Insegurança. Disponível em <http://www.slab.uff.br/textos/texto64.pdf>. Acesso em 15 de agosto de 2011.

EAVES, David. Alicerces da democracia. Correio Braziliense, Brasília, 13/05/2011. Caderno Tecnologia, p. 16.

FERNANDES, Hilton Cesário; ALMEIDA, Ludmila C. Políticos na Internet: Estímulo à participação política ou guerra dos egos? $7^{\circ}$ Encontro da $\mathrm{ABCP}$, Recife, Pernambuco, 4 a 7 de agosto de 2010.

GOTTDIENER, Mark. o debate sobre a teoria do espaço. In: A produção do espaço urbano. São Paulo: Edusp, 1993.

LEFEBVRE, Henry. O direito a cidade. São Paulo: Centauro, 2001.

JACOBS, Jane. A natureza - peculiar das cidades. In: Morte e vida de grandes cidades. São Paulo: Martins Fontes, 2000.

MAFFESOLI, M. O tempo das tribos - declínio do individualismo nas sociedades de massa. Rio de Janeiro: Forense Universitária, 2000. 
MIGUEL, Luis Felipe. Representação política em 3D, Elementos para uma teoria ampliada da representação política. Revista Brasileira de Ciências Sociais Vol. 18 N.o $51 \mathrm{fev} / 2003$.

PARK, Robert E. A cidade: sugestões para a investigação do comportamento humano no meio urbano. In VELHO, Gilberto (org.). 0 fenômeno urbano. $2^{\text {a }}$ Ed. Rio de Janeiro: Zahar Editora, 1973.

PASTANA, Débora Regina. Cultura do medo e democracia: um paradoxo brasileiro. In: Revista Medições. V. 10/ N. 2, Londrina, 2005 - P.183-198

PEREIRA, Natasha Bachini. Sob o Piado do Twitter: o Novo Tom das Campanhas Eleitorais com a Difusão da Internet no Brasil - Versão Reformulada. In: Seminário Nacional Sociologia \& Política, 2011, Universidade Federal do Paraná, Curitiba, Paraná.

SANTOS JR. Orlando A. dos; RIBEIRO, Luiz Cezar de; AZEVEDO, Sérgio de. Governança democrática e poder local: a experiência dos conselhos municipais no Brasil. Rio de Janeiro: Revan/Fase, 2004.

- Mudanças e Permanências na Cultura Política das Metrópoles Brasileiras. In: Dados - v. 52. Revista de Ciências Sociais. Rio de Janeiro: Iuperj, 2009 p. 691-733.

SOUZA, Jesse . A Construção Social da Subcidadania: para uma sociologia política da modernidade periférica. Belo Horizonte:Editorafg; Rio de Janeiro: IUPERJ, 2003.

WEBER, Max. Tipologia das cidades. In: VELHO, Gilberto (Org.). O Fenômeno Urbano.2 ${ }^{\text {a }}$ Ed.. Rio de Janeiro: Zahar, 1973.

WIRTH, Louis. $\mathrm{O}$ urbanismo como modo de vida. In: $\mathrm{O}$ fenômeno urbano. $2^{\mathrm{a}} \mathrm{Ed}$. Rio de Janeiro: Zahar Editora, 1973.

ZHANG, Weiwu; JOHNSON, Thomas J,; SELTZER, Trent; BICHARD, Shannon L. Political Attitudes and Behavior The Revolution Will be Networked: The Influence of Social Networking Sites on. Social Science Computer Review 2010; originally published online Jun 12, 2009.

\section{COMPOIITICA} ASSOCIACAO BRASILEIRA DE PESQUISADORES EM COMUNICACAO E POLÍTICA

Presidente: Alessandra Aldé (UERJ)

Vice-Presidente: Luis Felipe Miguel (UnB)

Secretário Executivo: Francisco Jamil Marques (UFC)

Editora-Chefe:

Alessandra Aldé (UERJ)

Editores Executivos:

Edna Miola (UFS) e Viktor Chagas (UFF)

Editores Assistentes:

Eleonora Magalhães (UFF) e Fernanda Sanglard (UERJ)
A Revista Compolítica é uma revista eletrônica da Associação Brasileira de Pesquisadores em Comunicação e Política. Com periodicidade semestral, sua proposta é difundir a produção acadêmica relacionada às interfaces desses campos de estudo.

\section{Ao citar este artigo, utilize a seguinte referência bibliográfica}

FERNANDES, Luiz Carlos do Carmo. Tecnologia a serviço da cidadania. In: Revista Compolítica, n. 3, vol. 2, ed. julhodezembro, ano 2013. Rio de Janeiro: Compolítica, 2013. 
